\title{
Structural Parameters and Working Range Estimation of Excavator Backhoe Mechanism
}

\author{
J Subba Raju, Basavaraju S
}

\begin{abstract}
Earthmoving machines like excavators and loaders characteristics such as productivity, weight, reliability depend on their backhoe mechanism. For that, the backhoe mechanism has to deliver the desired working range, digging forces and stability which are dependent on structural parameters like components length and joint angles. This paper describes the method of developing a backhoe mechanism for the desired working range which constitutes cutting heights and reaches by using structural parameters. This requires to develop forward kinematical model by considering the backhoe mechanism as a mechanical manipulator. A computer algorithm was developed, that uses the forward kinematic model, to estimate the working range. Also, a relationship is established between joint angles and cylinder lengths. Results of Virtual prototype, modeled and simulated in MSC ADAMS along with the testing results of BEML designed Physical prototype were used to validate the working range and structural parameters. This research provides a solid foundation for analyzing the effect of structural parameters on digging forces and stability.
\end{abstract}

Index Terms-Earthmoving machine, Backhoe mechanism, Structural parameters, Working range.

\section{INTRODUCTION}

Backhoe excavators are mechanical-hydraulic-electrical machines employed to excavate the material/iron ore from mining areas and construction sites. Performance of these machines depends on their backhoe mechanism operating characteristics such as working range, arm crowd force, breakout force and lifting capabilities. These characteristics which are dependent on structural parameters such as boom length, arm length, bucket length and their respective joint angles should be estimated, that makes mechanism reliable, light and efficient. Working range of the mechanism refers to reach of the bucket which includes maximum cutting height, maximum digging depth, maximum horizontal reach and minimum horizontal reach. Backhoe mechanism is a planar open loop kinematic chain in which links namely boom, arm and bucket are serially connected to each other with a pin joint. These structural links are actuated by boom cylinder, arm cylinder, and bucket cylinder respectively.

Researchers like P. k. vaha and J M. J. Skibniewski [1] reported the forward kinematical model of the backhoe mechanism in international journals. Further, Koivo A J [2]

Revised Manuscript Received on September 22, 2019.

J Subba Raju, Basavaraju S R\&D Division, KGF Complex, BEML LIMITED, KGF - 563115, Karnataka, India gave insight into the development of a kinematics model of backhoe excavator. S. Frimpong and Y. Li [6] presented the simulation of hydraulic shovel in a virtual environment[9], [11], [12]. However, the presentation of the complete kinematic model of the backhoe mechanism is not done.

Estimation of working range and the effect of structural parameters on the working range was not presented. One to one validation of working range parameters was not carried out effectively between the theoretical model and the physical prototype. Also, attempts were not made in analyzing the backhoe mechanism from the design point of view.

This paper emphasizes on developing of backhoe mechanism for desired working range by using structural parameters. Working range objectives set for the mechanism are maximum cutting height, maximum digging depth, maximum horizontal reach and minimum horizontal reach. To achieve these objectives, a forward kinematic model which is a function of joint angles and link lengths was developed to trace the tip of the backhoe bucket. Finding of working range consists of steps that usually have to be repeated many times. For that, a computer algorithm is developed, which uses the kinematic model, that was used in obtaining the working range. This algorithm will be used extensively in optimizing the spatial envelope of a mechanism. Subsequently, hydraulic cylinder lengths are found by establishing the mathematical relationship between joint angles and cylinder lengths. Automatic Dynamic Simulation of Mechanical Systems (ADAMS) /View module is a motion simulation software being used for validating the mathematical model. This paper presents a designer perspective of an excavator. Section2 describes the mathematical modelling of backhoe kinematics and its computer algorithm with a flowchart. Section 3 describes the virtual prototype modelling and simulation. Section4 describes the physical prototype and the validation of working range. Section5 evaluates the results and presents the results and relative comparison between the mathematical model, the virtual model and the physical prototype. Section6 presents the conclusion part.

\section{MATHEMATICAL MODELING OF THE BACKHOE MECHANISM}

\section{A. Kinematics modeling of the backhoe mechanism:}

The forward kinematics of a backhoe excavator refers to the calculation of the position of bucket tip point $F$ by using lengths of boom, arm, bucket and joint angles. Fig. 1 shows the schematic diagram of the backhoe excavator kinematics 


\section{Structural Parameters and Working Range Estimation of Excavator Backhoe Mechanism}

developed by M/s. BEML LIMITED. The excavator backhoe mechanism is a 12-bar linkage mechanism with three degree-of-freedom. In this research paper, swinging motion of the upper structure has been ignored. Undercarriage, upper structure are together considered as a base. Four positions $\left(\mathrm{O}_{\mathrm{E}}, \mathrm{O}_{\mathrm{B}}, \mathrm{O}_{\mathrm{A}}, \mathrm{O}_{\mathrm{BU}}\right)$ which include three joints and base are identified for attaching the right-handed coordinate frame as per Denavit-Heternberg convention[1]-[6], [8], [11]-[12] as described below. D-H parameters of the mechanism shown in table I.

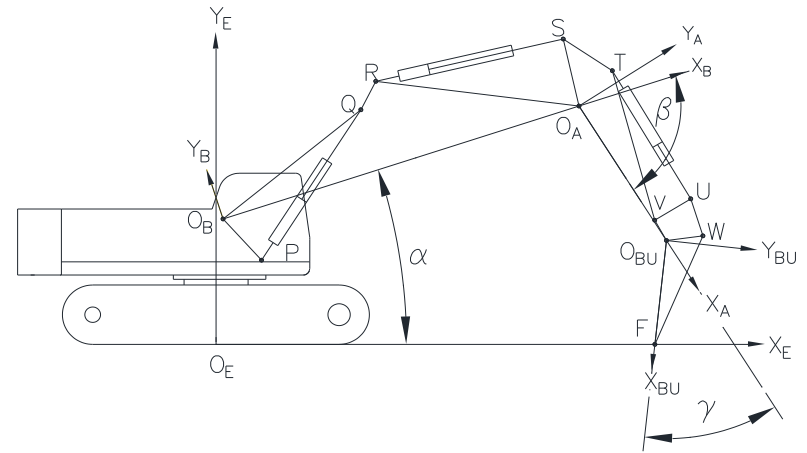

Fig.1. Kinematic layout of the excavator backhoe mechanism

Table I: Structural kinematic parameters

\begin{tabular}{|c|c|c|c|c|}
\hline & $\mathrm{a}$ & $\alpha$ & $\mathrm{d}$ & $\theta$ \\
\hline Boom & $\mathrm{L}_{\mathrm{a}}$ & 0 & 0 & $\alpha$ \\
\hline Arm & $\mathrm{L}_{\mathrm{b}}$ & 0 & 0 & $\beta$ \\
\hline Bucket & $\mathrm{L}_{\mathrm{bu}}$ & 0 & 0 & $\gamma$ \\
\hline
\end{tabular}

- $\left(\mathrm{X}_{\mathrm{E}}, \mathrm{Y}_{\mathrm{E}}, \mathrm{Z}_{\mathrm{E}}\right)$ is a fixed coordinate frame attached to equipment at point $\mathrm{O}_{\mathrm{E}}$.

- $\mathrm{O}_{\mathrm{B}}\left(\mathrm{X}_{\mathrm{B}}, \mathrm{Y}_{\mathrm{B}}, \mathrm{Z}_{\mathrm{B}}\right)$ is a coordinate frame attached to the boom at joint $\mathrm{O}_{\mathrm{B}}$ where $\mathrm{X}_{\mathrm{B}}$ is aligned with $\mathrm{O}_{\mathrm{B}} \mathrm{O}_{\mathrm{A}}$.

- $\mathrm{O}_{\mathrm{A}}\left(\mathrm{X}_{\mathrm{A}}, \mathrm{Y}_{\mathrm{A}}, \mathrm{Z}_{\mathrm{A}}\right)$ is a coordinate frame attached to the arm at joint $\mathrm{O}_{A}$ where $\mathrm{X}_{\mathrm{A}}$ is aligned with $\mathrm{O}_{\mathrm{A}} \mathrm{O}_{\mathrm{BU}}$.

- $\mathrm{O}_{\mathrm{BU}}\left(\mathrm{X}_{\mathrm{BU}}, \mathrm{Y}_{\mathrm{BU}}, \mathrm{Z}_{\mathrm{BU}}\right)$ is a coordinate frame attached to the bucket at joint $\mathrm{O}_{\mathrm{BU}}$ where $\mathrm{X}_{\mathrm{BU}}$ is aligned with $\mathrm{O}_{\mathrm{BU}} \mathrm{F}$.

- $\alpha$ is a joint angle at joint $\mathrm{O}_{\mathrm{B}}$ measured in a counterclockwise direction from $\mathrm{X}_{\mathrm{E}} \mathrm{TO} \mathrm{X}_{\mathrm{B}}$

- $\beta$ is a joint angle at joint $\mathrm{O}_{\mathrm{A}}$ measured in a counterclockwise direction from $\mathrm{X}_{\mathrm{B}} \mathrm{TO} \mathrm{X}_{\mathrm{A}}$

- $\gamma$ is a joint angle at joint $\mathrm{O}_{\mathrm{BU}}$ measured in a counterclockwise direction from $\mathrm{X}_{\mathrm{A}}$ To $\mathrm{X}_{\mathrm{BU}}$

- $\mathrm{L}_{\mathrm{b}}$ is the distances between $\mathrm{O}_{\mathrm{B}}$ to $\mathrm{O}_{\mathrm{A}}$ along $\mathrm{X}_{\mathrm{B}}$, i.e. Length of the boom.

- $\mathrm{L}_{\mathrm{a}}$ is the distances between $\mathrm{O}_{\mathrm{A}}$ to $\mathrm{O}_{\mathrm{BU}}$ along $\mathrm{X}_{\mathrm{A}}$, i.e. Length of the arm.

- $\mathrm{L}_{\mathrm{bu}}$ is the distances between $\mathrm{O}_{\mathrm{BU}}$ to $\mathrm{F}$ along $\mathrm{X}_{\mathrm{BU}}$, i.e. Length of the bucket.

- $\mathrm{X}$ is the distance between point $\mathrm{O}_{\mathrm{B}}$ and $\mathrm{O}_{\mathrm{E}}$ along $\mathrm{X}_{\mathrm{E}}$ direction.
- $\mathrm{Y}$ is the distance between point $\mathrm{O}_{\mathrm{B}}$ and $\mathrm{O}_{\mathrm{E}}$ along $\mathrm{Y}_{\mathrm{E}}$ direction.

Point $\mathrm{F}$ was expressed with respect to the equipment reference frame $\mathrm{O}_{\mathrm{E}}\left(\mathrm{X}_{\mathrm{E}}, \mathrm{Y}_{\mathrm{E}}, \mathrm{Z}_{\mathrm{E}}\right)$ by the use of the homogeneous transformation matrix $\mathrm{H}_{\mathrm{BU}}^{\mathrm{E}}$, which can be obtained by multiplying successive homogenous transformation matrices [8].

- $\mathrm{H}_{\mathrm{BU}}^{\mathrm{A}}$ gives the position and orientation of $\mathrm{O}_{\mathrm{BU}}\left(\mathrm{X}_{\mathrm{BU}}\right.$, $\left.\mathrm{Y}_{\mathrm{BU}}, \mathrm{Z}_{\mathrm{BU}}\right)$ coordinate frame with respect to $\mathrm{O}_{\mathrm{A}}\left(\mathrm{X}_{\mathrm{A}}\right.$, $\left.\mathrm{Y}_{\mathrm{A}}, \mathrm{Z}_{\mathrm{A}}\right)$

- $\mathrm{H}_{\mathrm{A}}^{\mathrm{B}}$ gives the position and orientation of $\mathrm{O}_{\mathrm{A}}\left(\mathrm{X}_{\mathrm{A}}, \mathrm{Y}_{\mathrm{A}}\right.$, $\left.\mathrm{Z}_{\mathrm{A}}\right)$ coordinate frame with respect to $\mathrm{O}_{\mathrm{B}}\left(\mathrm{X}_{\mathrm{B}}, \mathrm{Y}_{\mathrm{B}}\right.$, $\left.\mathrm{Z}_{\mathrm{B}}\right)$

- $\mathrm{H}_{\mathrm{B}}^{\mathrm{E}}$ gives the position and orientation of $\mathrm{O}_{\mathrm{B}}\left(\mathrm{X}_{\mathrm{B}}, \mathrm{Y}_{\mathrm{B}}\right.$, $\left.\mathrm{Z}_{\mathrm{B}}\right)$ coordinate frame with respect to $\mathrm{O}_{\mathrm{E}}\left(\mathrm{X}_{\mathrm{E}}, \mathrm{Y}_{\mathrm{E}}, \mathrm{Z}_{\mathrm{E}}\right)$

$$
\mathrm{H}_{\mathrm{BU}}^{\mathrm{E}}=\mathrm{H}_{\mathrm{B}}^{\mathrm{E}} * \mathrm{H}_{\mathrm{A}}^{\mathrm{B}} * \mathrm{H}_{\mathrm{BU}}^{\mathrm{A}}
$$

$$
\mathrm{H}_{\mathrm{BU}}^{\mathrm{A}}=R(Z, \gamma) T\left(L_{a}, 0,0\right)=\left[\begin{array}{cccc}
\cos \gamma & -\sin \gamma & 0 & \mathrm{~L}_{\mathrm{a}} \\
\sin \gamma & \cos \gamma & 0 & 0 \\
0 & 0 & 1 & 0 \\
0 & 0 & 0 & 1
\end{array}\right]
$$

$$
\mathrm{H}_{\mathrm{A}}^{\mathrm{B}}=R(Z, \beta) T\left(L_{b}, 0,0\right)=\left[\begin{array}{cccc}
\cos \beta & -\sin \beta & 0 & \mathrm{~L}_{\mathrm{b}} \\
\sin \beta & \cos \beta & 0 & 0 \\
0 & 0 & 1 & 0 \\
0 & 0 & 0 & 1
\end{array}\right]
$$

$$
\mathrm{H}_{\mathrm{B}}^{\mathrm{E}}=R(Z, \alpha) T(X, Y, 0)=\left[\begin{array}{cccc}
\cos \alpha & -\sin \alpha & 0 & \mathrm{X} \\
\sin \alpha & \cos \alpha & 0 & \mathrm{Y} \\
0 & 0 & 1 & 0 \\
0 & 0 & 0 & 1
\end{array}\right]
$$

$$
\mathrm{F}^{\mathrm{O}_{\mathrm{E}}}=\left[\begin{array}{c}
\mathrm{X}_{\mathrm{E}} \\
\mathrm{Y}_{\mathrm{E}} \\
\mathrm{Z}_{\mathrm{E}} \\
1
\end{array}\right]=\mathrm{H}_{\mathrm{BU}}^{\mathrm{E}} *\left[\begin{array}{c}
\mathrm{L} \_b u \\
0 \\
0 \\
1
\end{array}\right]
$$

The (5) will give $\mathrm{x}, \mathrm{y}$ coordinates of point $\mathrm{F}$ with respect to $\mathrm{O}_{\mathrm{E}}\left(\mathrm{X}_{\mathrm{E}}, \mathrm{Y}_{\mathrm{E}}, \mathrm{Z}_{\mathrm{E}}\right)$ coordinate system for the given lengths of links and their orientation, i.e. $\mathrm{L}_{\mathrm{b}}, \mathrm{L}_{\mathrm{a}}, \mathrm{L}_{\mathrm{bu}}, \alpha, \beta$ and $\gamma$.

\section{B. Computer Algorithm}

A computer algorithm was developed to get the point $\mathrm{F}$ over the entire working range. The algorithm was represented in the form of the flowchart as shown in fig. 2 in which joint angles and link lengths are declared as variables. 


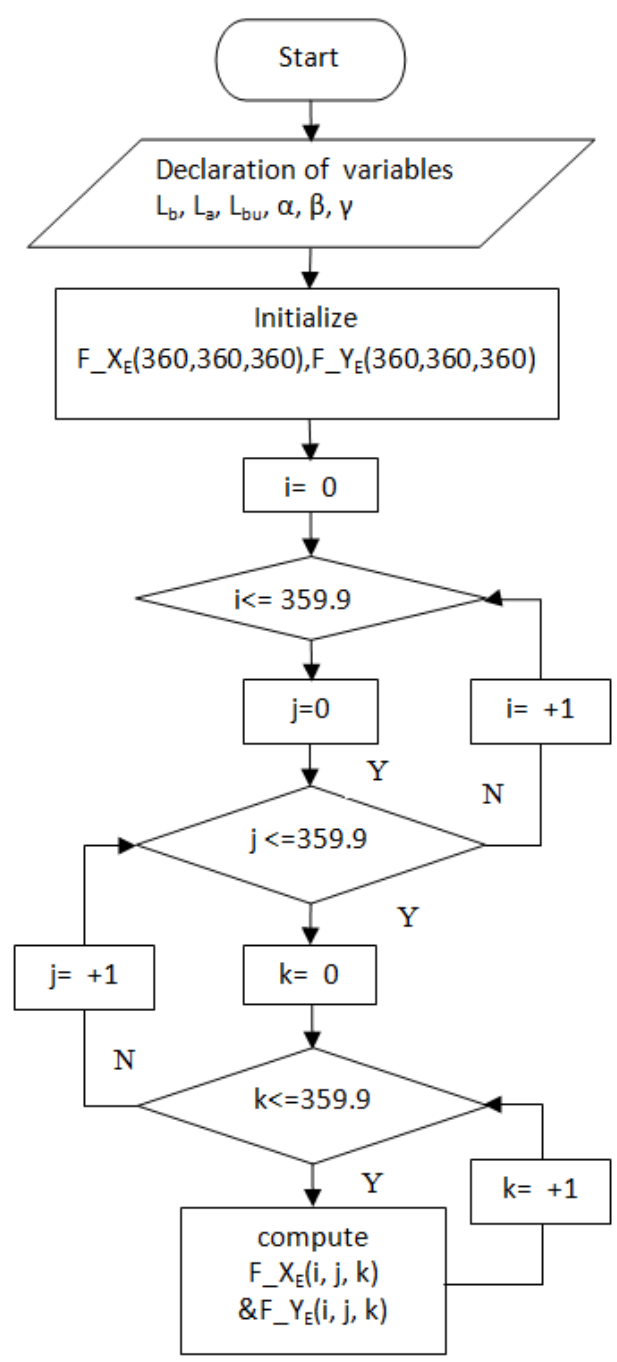

Fig. 2. Flow-chart for computation of point $F_{-} X_{E}, F_{-} Y_{E}$

For a given backhoe mechanism, length of the boom, arm and bucket are fixed whereas joint angle $\alpha$ varies from $\alpha 1$ to $\alpha 2, \beta$ varies from $\beta 1$ to $\beta 2$ and $\gamma$ varies from $\gamma 1$ to $\gamma 2$ over a working range. The point $\mathrm{F}$ is calculated for every value of $\alpha$, $\beta$, and $\gamma$, so that the entire working range is covered by using (5). All F points are plotted graphically as shown in fig.3, which will give the vivid description about geometrical details of working range limits of the given backhoe mechanism, such as maximum cutting height, maximum digging depth, maximum reach and minimum reach. $F_{-} X_{E}$, $\mathrm{F}_{-} \mathrm{Y}_{\mathrm{E}}$ are declared as three-dimensional arrays to store the values of $\mathrm{F}$ for the three joint angle variables. To obtain the value of $F_{-} X_{E}(360,360,360)$ and $F_{-} Y_{E}(360,360,360)$, one can use iteration starting with zero initialization. In this flowchart, we are iterating using 3 'for' loops. Declaration of corresponding loop variables is followed by initialization to their respective zero-values. Three iteration variables $\mathrm{i}, \mathrm{j}$ and $\mathrm{k}$ are used to keep track of the iteration and are initialised to zero. i covers outer loop, $\mathrm{j}$ covers middle loop, and $\mathrm{k}$ covers the innermost loop. Conditional checking is done from 0 to 359.9 with an increment of 1 for every iteration. No statements are included other than 'for' in i, j loops. $\mathrm{k}$ loop contains the calculation of $F_{-} X_{E}(i, j, k)$ and $F_{-} Y_{E}(i, j$, $\mathrm{k})$. This is done to make sure computation of $F_{-} X_{E}(i, j, k)$ and $F_{-} Y_{E}(i, j, k)$ is done in the order $k->j->i$, i.e. we can't compute $F_{-} X_{E} / F_{-} Y_{E}$ with argument $i$ without computing equal valued $j$, and also we can't compute $F_{-} X_{E} / F_{-} Y_{E}$ with argument $\mathrm{j}$ without computing equal valued $\mathrm{k}$. Data filtered from this algorithm that fits in the range of joint angles have been plotted as shown in fig.3.

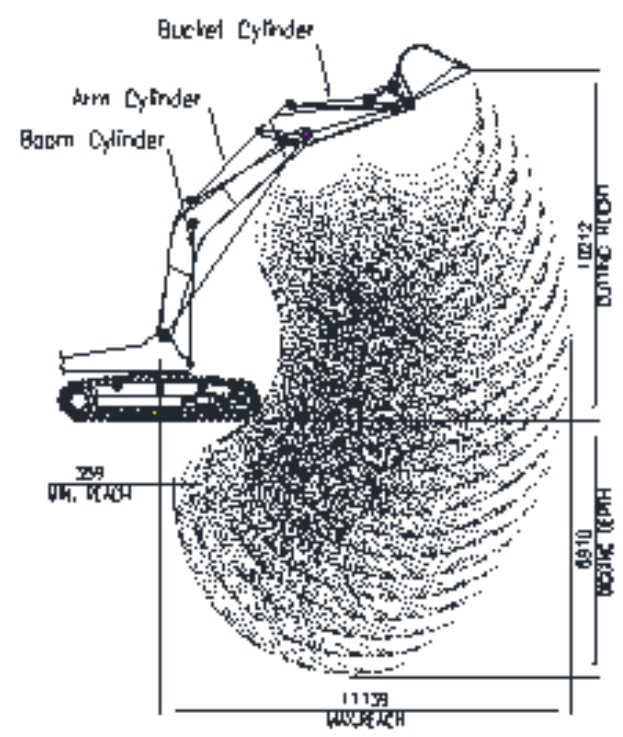

Fig. 3. Locus of the bucket tip

There are many possibilities to obtain the required working range by varying the lengths and tilt angles of attachment components. Analyzing the effect of each structural parameter on working range is very much necessary.

The following consideration to be considered during the development of mechanism.

- As $\gamma 1$ increases, Vertical wall depth increases which is very important for certain digging applications.

- Angle of $\gamma 2$ should be always greater than angle of repose of sand.

- Tilting range of bucket should not greater than $180^{\circ}$

\section{Relationship between joint angles and cylinder lengths}

Hydraulic cylinders will push the links to get the specified angular displacements by means of the linkage mechanism. Length of the cylinder is defined as a distance between two end mountings of a cylinder along the axis. The length of the cylinder is varying as joint angle varies. Mounting locations of hydraulic cylinders depends on space constraints, the minimum length of the cylinder which can be manufactured for a particular design, and optimum mechanical advantage of cylinder link. So it is essential to develop a mathematical relationship between joint angles and the length of the cylinder. The Principle of the loop closure equation is used to establish this. Geometrical

details containing mounting locations of the boom, arm, bucket and cylinders are shown fig. 4 .

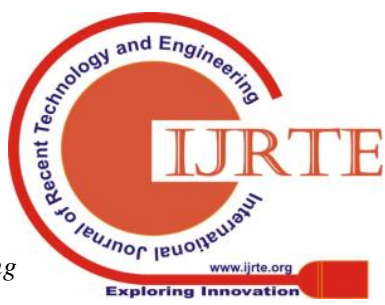




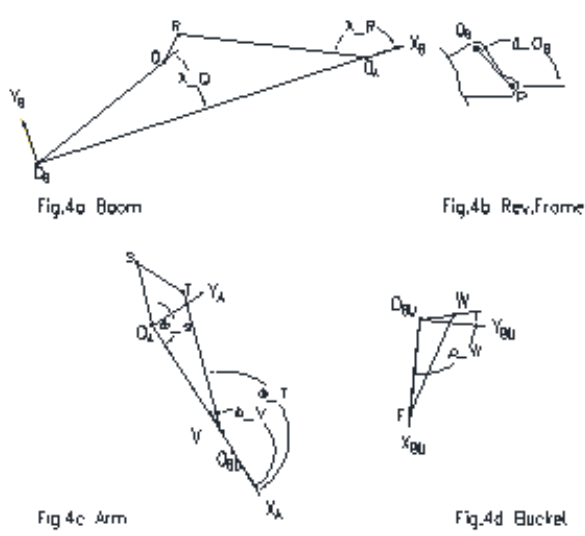

Fig. 4. Geometry of structural links

The lifting mechanism of work attachment is shown as vector diagram in fig. 5 in which boom cylinder, boom and upper structure forms a closed loop kinematic chain $\left(\mathrm{PO}_{\mathrm{B}} \mathrm{Q}\right)$. Loop closure equation [7] of kinematic chain is shown in (6).

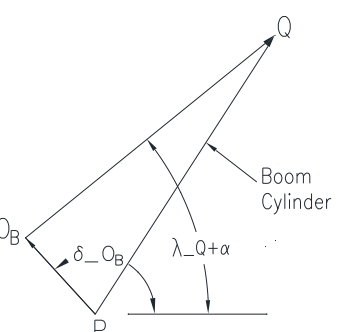

Fig.5. Vector diagram represents the relation between the $\mathrm{L}_{\mathrm{b}}$ and alpha

$$
\overrightarrow{P O_{B}}+\overrightarrow{O_{B} Q}-\overrightarrow{P Q}=0
$$

Vectors are replaced with their polar complex form and can be written as,

$$
\begin{aligned}
& \overrightarrow{P Q}=\left|\overrightarrow{P O_{B}}\right| * \cos \left(\delta_{-} O_{B}\right)+\left|\overrightarrow{O_{B} Q}\right| * \cos \left(\alpha+\lambda_{-} Q\right) \\
& +i *\left[\left|\overrightarrow{P O_{B}}\right| * \sin \left(\delta_{-} O_{B}\right)+\left|\overrightarrow{O_{B} Q}\right| * \sin \left(\alpha+\lambda_{-} Q\right)\right]
\end{aligned}
$$

The mechanism for actuating arm is shown as vector diagram in fig.6 in which Arm cylinder, Arm, and boom forms closed loop kinematic chain $\left(\mathrm{O}_{\mathrm{A}} \mathrm{RS}\right)$.Loop closure equation [7] of kinematic chain is shown in (8).

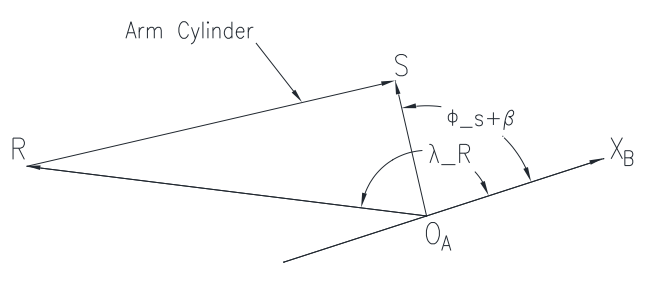

Fig.6. Vector diagram represents the relation between the $L_{a}$ and beta

$\overrightarrow{O_{A} R}+\overrightarrow{R S}-\overrightarrow{O_{A} S}=0$
Vectors are replaced with their polar complex form and can be written as,

$$
\begin{aligned}
& \overrightarrow{R S}=-\left|\overrightarrow{O_{A} R}\right| * \cos \left(\lambda_{-} R\right)+\left|\overrightarrow{O_{A} S}\right| * \cos \left(\varphi_{-} S+\beta\right) \\
& +i *\left[-\left|\overrightarrow{O_{A} R}\right| * \sin \left(\lambda_{-} R\right)+\left|\overrightarrow{O_{A} S}\right| * \sin \left(\varphi_{-} S+\beta\right)\right]
\end{aligned}
$$

Unlike the previous boom cylinder and arm cylinder mechanisms, the mechanism for bucket curl-in and curl-out, shown as vector diagram in fig.7, contains two closed kinematic loops. These two loops are: 1.closed kinematic loop chain (TVU) formed by arm cylinder, arm and arm link; 2. second closed loop is a four-bar kinematic chain $\left(\mathrm{VO}_{\mathrm{BU}} \mathrm{WU}\right)$ formed by arm, bucket, arm link and bucket link. This four-bar mechanism is used to leverage bucket cylinder force.

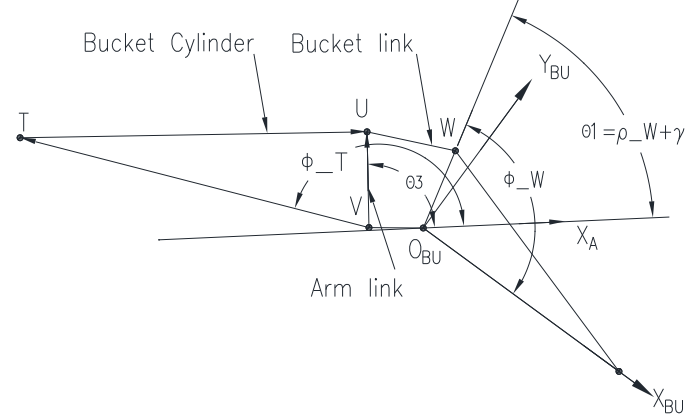

Fig. 7. Vector diagram represents the relation between the Lbu and gama

By using the 4-bar mechanism $\left(\mathrm{VO}_{\mathrm{BU}} \mathrm{WU}\right)$ formulated by the theory of Freudenstein, the relation between $\theta 3$ and $\theta 1$ (which is a function of game) was developed as shown in (10). Now that, the value of $\theta 3$ is known, we can establish the relationship between joint angle game and bucket cylinder length as shown below.

$\theta 3=2 * \tan ^{-1}\left(\frac{-k 1 \pm \sqrt{k 1^{2}+k 2^{2}-k 3^{2}}}{k 3-k 2}\right)$

Where,

$$
\begin{aligned}
& K 1=2 * L_{3} *\left[-L_{1} * \sin (\theta 1)+L_{0} * \sin \left(\varphi_{-} V\right)\right] \\
& K 2=2 * L_{3} *\left[-L_{1} * \cos (\theta 1)+L_{0} * \cos \left(\varphi_{-} V\right)\right. \\
& K 3=L_{0}^{2}+L_{1}^{2}-L_{2}^{2}+L_{3}^{2} \\
& -2 * L_{0} * L_{1} * \cos (\theta 1) * \cos \left(\varphi_{-} V\right) \\
& -2 * L_{0} * L_{1} * \sin (\theta 1) * \sin \left(\varphi_{-} V\right) \\
& L_{0}=\left|\overrightarrow{O_{B U} V}\right| \\
& L_{1}=\left|\overrightarrow{O_{B U} W}\right| \\
& (10.5) L_{2}=|\overrightarrow{U W}| \\
& (10.6) \\
& L_{3}=|\overrightarrow{V U}|
\end{aligned}
$$


Loop closure equation [7] of kinematic chain (TUV) is shown in (11).

$\overrightarrow{V T}+\overrightarrow{T U}-\overrightarrow{V U}=0$

Vectors are replaced with their polar complex forms and can be written as,

$$
\begin{aligned}
& \overrightarrow{T U}=-|\overrightarrow{V T}| * \cos \left(\varphi_{-} T\right)+|\overrightarrow{V U}| * \cos (\theta 3)+ \\
& i^{*}\left[-|\overrightarrow{V T}| * \sin \left(\varphi_{-} T\right)+|\overrightarrow{V U}| * \sin (\theta 3)\right]
\end{aligned}
$$

Joint angles that were finalized by the computer algorithm were used as input for finding the cylinder lengths. Equation.(7),(9) and (12) will give the length of cylinders according to their corresponding joint angles alpha, beta and gama respectively.

\section{KINEMATICS SIMULATION OF BACKHOE MECHANISM}

MSC ADAMS/View is a Multibody Dynamic Simulation Software that is used for modeling and simulation of the virtual prototype [6], ]9], [12] of the backHoe mechanism.

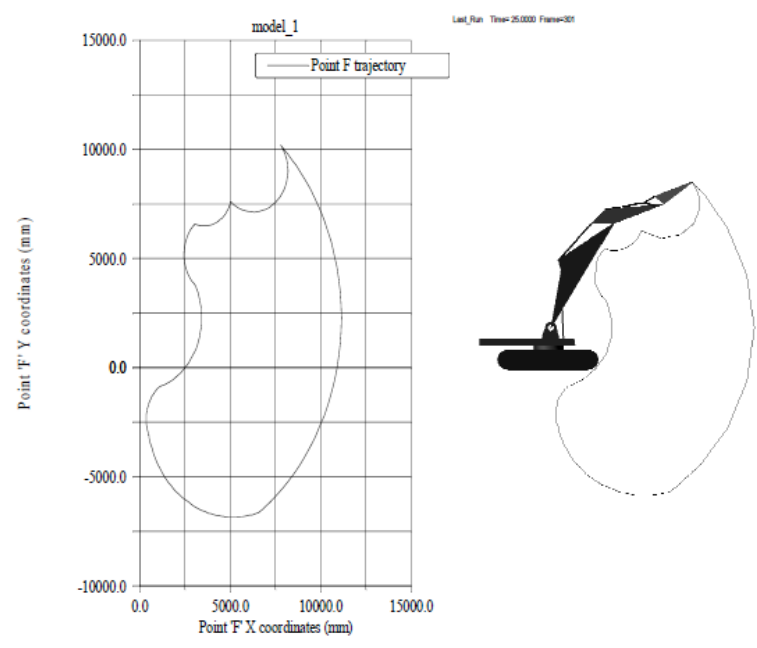

Fig. 8. Trajectory of the bucket tip

This virtual model, shown in fig. 8 , is the second stage of design. The validation is limited to the kinematics of the backhoe mechanism. So, the accuracy of parameters such as the mass of the structures, inertia and their topology is ignored. Attention is given to the modeling of kinematic points such as $\mathrm{O}_{\mathrm{B}}, \mathrm{O}_{\mathrm{A}}, \mathrm{O}_{\mathrm{BU}}, \mathrm{P}, \mathrm{Q}, \mathrm{R}, \mathrm{S}, \mathrm{T}, \mathrm{U}, \mathrm{V}$ and $\mathrm{W}$ as shown fig.1. Built-in primitives like plate and link were used for modeling of structures in MSC ADAMS/View environment. Kinematic constraints such as fixed, sliding and revolute joints are applied in kinematic pairs based on their relative motion. The undercarriage is added to the ground. Since swinging motion is ignored, a fixed joint is used between the upper Structure and the undercarriage. Except for hydraulic cylinder, which is sliding joint, remaining all are revolute joints. Measures were created for measuring joint angles and cylinder lengths during the run. These measures were used in validating the working range parameters, set in the mathematical model and computer algorithm. Linear motions are applied with 'step' function [9] to all sliding joints of cylinders to cover the entire working cycle which includes digging, loading and dumping of material.
Motion function for boom cylinder

,=STEP(time,0,0,3.6,1555)+STEP(time,10.1,0,13.3,-1555)

Motion function for arm cylinder,

$=\mathrm{STEP}($ time $, 3.6,0,8,-1850)+\mathrm{STEP}($ time $, 15.5,0,19.4,1850)$

Motion function for bucket cylinder,

STEP(time, $8,0,10.1,800)+$ STEP(time, 13.8,0,15.3,565)

+ STEP(time, 19.4,0,22.6,-1365)

The completed virtual prototype model was submitted to ADAMS/Solver to compute the motion behavior of mechanism and to write that information to output files. Tip of the bucket has been plotted along $x-y$ axes as shown in the fig.8, that shows the backhoe mechanism working envelope. Envelope limits such as Maximum cutting height, max digging depth, maximum reach and minimum reach were extracted from Fig. 8 and are shown in table II. By using the measures created in pre-processing, fig. 9 was plotted in post-processing. Fig. 9 show the corresponding variation of joint angle alpha and boom cylinder length, beta and arm cylinder length, gama and bucket cylinder length with time. Now with these simulations, the correlation between joint angles and cylinder lengths that were formulated in the mathematical model can be verified at any position of the mechanism. For the convenience of validation, initial positions of joint angles and corresponding cylinder length were taken from respective plots and tabulated in table II.

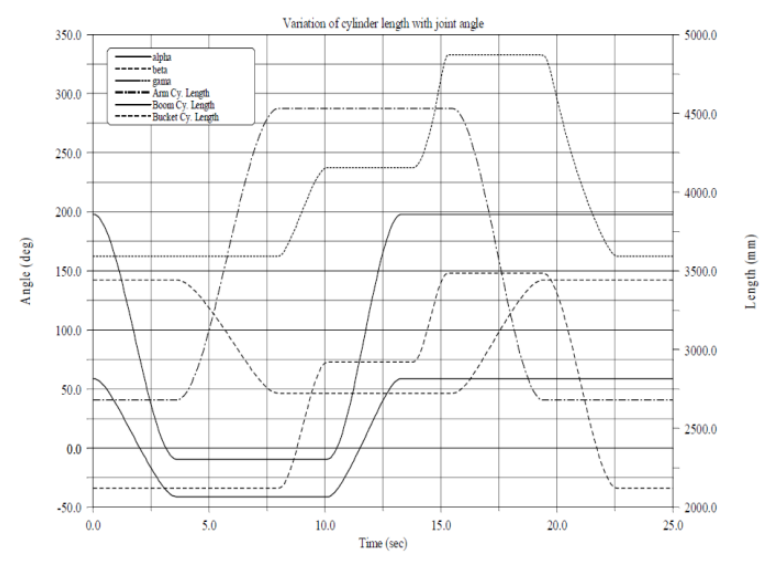

Fig.9. Variation of joint angles, with cylinder length

\section{Prototype evaluation}

Although attachment characteristics was estimated theoretically, more results can be achieved only while testing the prototype. These tests may result in other correction of linkage arrangement and components design. Physical prototype testing was carried out on BEML backhoe excavator for validating the mathematical model, computer algorithm and the virtual model. Working range parameters such as maximum cutting height, max digging depth, max. reach and min. reach were measured during testing of equipment and tabulated in table II. 


\section{RESULTS AND DISCUSSION}

This paper deals with three kinds of models. First is the mathematical model, second is the virtual model and the last is the physical prototype. Fig.11 shows the progress of design methodology and the convergence of the results. Objectives set in this paper are working range limits and cylinder lengths corresponding to joint angles were validated on all three models. The mathematical model is the first stage of the design process where a sufficient number of design iterations are carried out. An iteration which meets desired working range was used to prepare the virtual model. Since the geometrical input is same for the both models, variation in results can only emerge from kinematical relationships between parts. The kinematical relationship between rigid bodies is described through equations in the mathematical model whereas, in MSC ADAMS it has been defined through inbuilt tools.

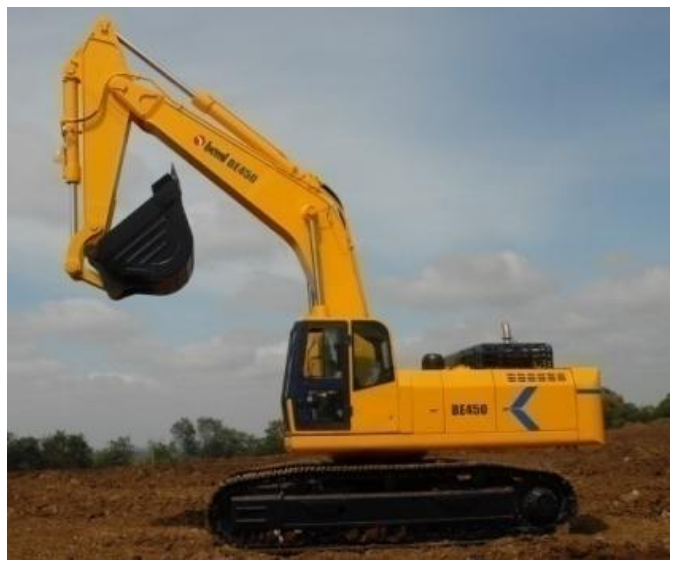

Fig. 10. Excavator in Testing

Working range limits which are obtained from computer algorithm are checked against the virtual model and the physical prototype. Cylinder lengths are derived from the mathematical model by using the principles of loop closure equations whereas, in ADAMS it has been measured in post-processing through inbuilt runtime measures. Table II shows the output data for all models. The deviation in values are within $0.5 \%$ which is acceptable limit as per IS. ISO 9248:1992.

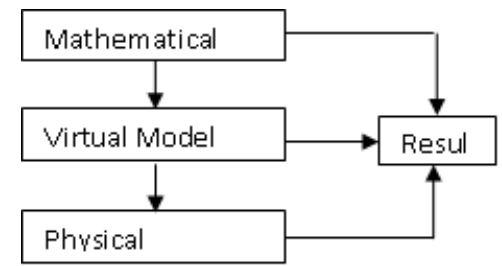

Fig. 11. Sequence of design and convergence results

\section{Conclusion}

Working range in one of the important characteristics of backhoe mechanism. To estimate the working range, a forward kinematical modal and its computer algorithm was developed. Working range computed from computer algorithm was validated with virtual and physical prototype of BEML designed excavator. Results were consistent and proved to be right. This paper emphasizes the significance of structural parameters of backhoe, sequence of design and design validation procedures. This work lays foundation for analyzing the backhoe from stability and digging forces point of view. Also, developing a customised tool in MSC Adams, which adapts the concept of mathematical modelling and its computer algorithm, will reduce the design efforts.

\section{ACKNOWLEDGEMENTS:}

This research was supported by M/s BEML LIMITED. I thank V. Sekar, GM, R\&D, BEML LTD, P. Vinaykumar, AGM, R\&D, BEML LTD for assistance and comments that significantly improved the manuscript.

\section{REFERENCES}

[1] P. K. Vähä and M. J. Skibniewski, "Dynamic Model of Excavator," Journal of Aerospace Engineering, vol. 6, no. 2, pp. $148-158,1993$.

[2] A. J. Koivo, "Kinematics of Excavators (Backhoes) for Transferring Surface Material," Journal of Aerospace Engineering, vol. 7, no. 1, pp. 17-32, 1994.

[3] A. J. Koivo, M. Thoma, E. Kocaoglan, and J. Andrade-Cetto, "Modeling and Control of Excavator Dynamics during Digging Operation," Journal of Aerospace Engineering, vol. 9, no. 1, pp. 10-18, 1996.

[4] C. F. Hofstra, A. J. M. V. Hemmen, S. Miedema, and J. V. Hulsteyn, "Describing the position of backhoe dredge buckets," 2000.

[5] S. Rao and P. Bhatti, "Probabilistic approach to manipulator kinematics and dynamics," Reliability Engineering \& System Safety, vol. 72, no. 1, pp. $47-58,2001$

[6] S. Frimpong and Y. Li, "Virtual prototype simulation of hydraulic shovel kinematics for spatial characterization in surface mining operations," International Journal of Surface Mining, Reclamation and Environment, vol. 19, no. 4, pp. 238-250, 2005.

[7] N. Demirel and S. Frimpong, "Dragline dynamic modelling for efficient excavation," International Journal of Mining, Reclamation and Environment, vol. 23, no. 1, pp. 4-20, 2009.

[8] J. Xu and H.-S. Yoon, "A Review on Mechanical and Hydraulic System Modeling of Excavator Manipulator System," Journal of Construction Engineering, vol. 2016, pp. 1-11, 2016.

[9] H. Yu, Y. Liu, and M. S. Hasan, "Review of modelling and remote control for excavators," International Journal of Advanced Mechatronic Systems, vol. 2, no. 1/2, p. 68, 2010.

[10] C. Xiao and G. Zhang, "Dynamic Simulation Analysis of Working Device for Hydraulic Excavator Based on ADAMS," TELKOMNIKA (Telecommunication Computing Electronics and Control), vol. 14, no. 3A, p. 194, 2016.

[11] Y. Li and W. Y. Liu, "Spatial Kinematics Modeling and Simulation of Wheel Loader," Journal of Modeling, Simulation, Identification, and Control, vol. 1, no. 2, pp. 78-88, Feb. 2013.

[12] Y. Li, S.-S. Chang, and W. Liu, "Spatial kinematics and virtual prototype modeling of Bucyrus shovel," The International Journal of Advanced Manufacturing Technology, vol. 69, no. 5-8, pp. 1917-1925, 2013.

[13] Ahmed, Syed Thouheed, M. Sandhya, and Sharmila Sankar. "A Dynamic MooM Dataset Processing Under TelMED Protocol Design for QoS Improvisation of Telemedicine Environment." Journal of medical systems 43, no. 8 (2019): 257.

[14] Ahmed, Syed Thouheed, M. Sandhya, and Sharmila Sankar. "An Optimized RTSRV Machine Learning Algorithm for Biomedical Signal Transmission and Regeneration for Telemedicine Environment." Procedia Computer Science 152 (2019): 140-149.

[15] Patil, Kiran Kumari, and Syed Thouheed Ahmed. "Digital telemammography services for rural India, software components and design protocol." In 2014 International Conference on Advances in Electronics Computers and Communications, pp. 1-5. IEEE, 2014.

[16] Thouheed, Syed, S. Ahmed, M. Sandhya, and S. Shankar. "ICT's Role in Building and Understanding Indian Telemedicine Environment: A Study." In Information and Communication Technology for Competitive Strategies. Lecture Notes in Networks and Systems, vol 40. Springer Singapore, 2019. 